\title{
Comparative morphology of pre-extrusion larvae, Sebastes mentella and Sebastes norvegicus (Pisces: Sebastidae) in Icelandic waters
}

\author{
A. R. Vergara*†, P. Sigurðsson** and F. Saborido-Rey* \\ *Instituto de Investigaciones Marinas, IIM-CSIC, Calle Eduardo Cabello 6, 36208 Vigo,Spain \\ and **Marine Research Institute, Skulagotu 4, 101 Reykjavik, Iceland \\ † Tel.: +34 986231930; email: albarvergara@iim.csic.es
}

\begin{abstract}
This study evaluated potential differences in morphology of unextruded larvae from Sebastes mentella and Sebastes norvegicus in Icelandic waters. Fifty-four larvae of each species were measured, and 18 measurements were recorded for each specimen (morphometric, meristic and pigmentation patterns). Preextrusion larvae of $S$. norvegicus were longer than those of $S$. mentella. Additionally, there were significant differences in morphometric, meristic and pigmentation characters between pre-extrusion larvae of these species. Pigmentation of $S$. mentella differed from that of $S$. norvegicus in several aspects. Dorsal and ventral body pigmentation tended to begin more posteriorly in $S$. mentella, therefore, the overall length of these pigmented areas tended to be longer in $S$. norvegicus.
\end{abstract}

Key words: meristics; morphology; North Atlantic Ocean; pigmentation; redfish.

\section{INTRODUCTION}

Redfish (genus Sebastes) are members of the species-rich family Sebastidae; in the North Atlantic Ocean Sebastes is represented by four species. North Atlantic redfish species are morphologically remarkably similar; therefore, their identification has been controversial and remains difficult because of overlapping meristic and other morphological characters $(\mathrm{Ni}, 1982$; Power \& Ni, 1985; Rubec et al., 1991; Saborido-Rey, 1994; Pampoulie \& Daníelsdóttir, 2008).

Sebastes are viviparous, the eggs being fertilized internally (Saborido-Rey et al., 2004), and spawning is characterized by the parturition or extrusion of between 40000 and 400000 pelagic larvae annually (Magnússon \& Magnússon, 1995). Embryonic development within gonads of individual Sebastes is synchronous. After parturition, Sebastes larvae lead a pelagic existence of varying duration, and are one of the most abundant fish larvae in the Irminger Sea south-west of Iceland and off the Flemish Cap $\left(47^{\circ} \mathrm{N} ; 45^{\circ} \mathrm{W}\right)$ throughout all years and seasons surveyed (Serebryakov et al., 1984). Discrimination of species among redfish larvae is complex because the morphological characters used for adults and juveniles cannot be used for identifying species during the larval stages (Penney, 1987). Also, none of the characters studied for larvae has given clear separation of species (Moser et al., 1977; Serebryakov, 1982).

The ability to identify larvae of Sebastes has increased dramatically in recent years. They are easily recognized as members of Sebastes (Moser et al., 1977; Matarese et al., 1989; Moser, 1996), but the early stages have not yet developed species-distinguishing characteristics and incorrect identifications have complicated descriptions of larvae of Sebastes from the North Atlantic Ocean (Magnússon, 1981; Penney, 1985; Kendall, 1991; Moser \& Boehlert, 1991; Gray et al., 2006). 
Thus, a detailed examination of the morphology of unextruded larvae of Sebastes mentella Travin 1951 and Sebastes norvegicus (Ascanius 1772) [regarded as a name valid by some authors as much as Sebastes marinus (L. 1758), Eschmeyer (2012)] was carried out. The characters (morphometrics, meristic and pigmentation variables) were examined as potential criteria for species identification, based on a comparative morphology of unextruded larvae from females in the area of south-west Iceland.

\section{MATERIALS AND METHODS}

Sampling locations covered mainly the fishing grounds around Iceland. The collection of samples followed general agreement among researchers involved in the REDFISH project (unpubl. data) during 2000 and 2002. In this project, characteristics of gas-bladder musculature were used to identify adults of $S$. mentella and $S$. norvegicus (Saborido-Rey, 1994). Adult female S. mentella and $S$. norvegicus containing larvae were collected off south-west Iceland by stratified random bottom trawling from research surveys. The sampling strategy was to process specimens $>25 \mathrm{~cm}$ total length $\left(L_{\mathrm{T}}\right)$, because smaller specimens are considered to be immature (Saborido-Rey, 1994). Gonads were removed, placed in microperforated plastic bags and then placed in a plastic barrel with $3,6 \%$ buffered formaldehyde.

Late-stage pre-extrusion larvae of both species, with yolk sacs fully reabsorbed or nearly so, were used in a comparative morphological analysis. Only fully developed larvae were used to ensure that interspecific differences were not affected by variations in developmental stage. Because of this requirement, only 7 of 103 ovaries showed suitable late-stage pre-extrusion larvae (7\%). Three female S. norvegicus were collected in 2000 and four female $S$. mentella were collected in 2002.

All other gonads of collected Sebastes either contained unhatched eggs or hatched larvae in early developmental stages (93\%). The percentage of suitable larvae that were collected from the gonads and in good condition to be photographed and measured was low because of prolonged preservation. Consequently, only randomly selected samples of 54 larvae were measured from each species.

Several images were taken of each larva with a video camera connected to a stereo microscope. All photographed larvae were measured using the software QWin (Leica Imaging Systems; www.leicamicrosystems.com). A total of five morphometric measurements were taken (Fig. 1), comprising: (1) standard length $\left(L_{\mathrm{S}}\right)$, the distance along the midline of the body from the tip of the snout to the end of the urostyle; (2) pre-anal length $\left(L_{\mathrm{PRA}}\right)$, the distance along the midline of the body from the tip of the snout to the anus; (3) head depth $\left(H_{D}\right)$, along a vertical line through the centre of the eye; (4) body depth at the anus $\left(B_{\mathrm{D}}\right)$ and $(5)$ eye diameter $\left(D_{\mathrm{E}}\right)$, maximum horizontal eye diameter.

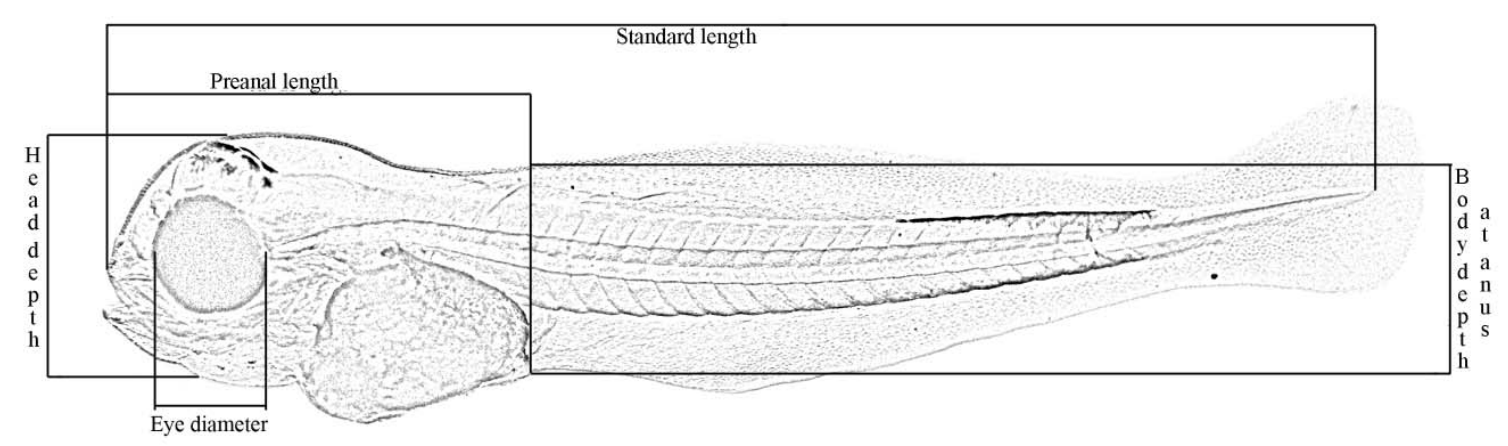

Fig. 1. Sebastes spp. larva showing base points for measurements. 
Three meristic measurements were recorded, comprising: total body myomeres $(M)$, number of preanal myomeres $\left(M_{\mathrm{PRA}}\right)$ and number of postanal myomeres $\left(M_{\mathrm{POA}}\right)$. Furthermore, a total of 10 pigmentation patterns were recorded, comprising: postanal myomere on which the anteriormost melanophore on the dorsum begins $\left(P_{\mathrm{D}-\mathrm{B}}\right)$ and ends $\left(P_{\mathrm{D}-\mathrm{E}}\right)$; postanal myomere on which the anteriormost melanophore on the ventrum begins $\left(P_{\mathrm{V}-\mathrm{B}}\right)$ and ends $\left(P_{\mathrm{V}-\mathrm{E}}\right)$; total length, in myomeres, of the dorsal $\left(P_{\mathrm{D}-\mathrm{T}}\right)$ and the ventral body melanophore line $\left(P_{\mathrm{V}-\mathrm{T}}\right)$ and melanophore pattern located on the ventrum $\left(P_{\mathrm{V}}\right)$, at the nape $\left(P_{\mathrm{N}}\right)$, on the dorsum $\left(P_{\mathrm{D}}\right)$ and on top of the brain $\left(P_{\mathrm{H}}\right.$, see Table $\left.\mathrm{I}\right)$.

Table I. Pigmentation patterns of pre-extrusion larvae of Sebastes mentella and Sebastes norvegicus.

\begin{tabular}{|c|c|c|c|c|}
\hline Melanophores & 1 & 2 & 3 & 4 \\
\hline $\begin{array}{c}\text { On the ventrum } \\
M_{\mathrm{V}}\end{array}$ & Expanded, separate & $\begin{array}{l}\text { Expanded, not } \\
\text { separate }\end{array}$ & $\begin{array}{l}\text { Expanded, separate } \\
+ \text { not separate }\end{array}$ & $\begin{array}{c}\text { Expanded }+ \\
\text { contracted }\end{array}$ \\
\hline $\begin{array}{l}\text { At the nape } \\
\qquad M_{\mathrm{N}}\end{array}$ & Single expanded & $\begin{array}{l}\text { One or more } \\
\text { contracted }\end{array}$ & No pigment & No pigment \\
\hline $\begin{array}{c}\text { On the dorsum } \\
M_{\mathrm{D}}\end{array}$ & $\begin{array}{l}\text { Line for more than } \\
\text { half the total extent } \\
\text { of the melanophore } \\
\text { pattern }\end{array}$ & $\begin{array}{l}\text { Line less than half } \\
\text { the total extent of } \\
\text { the melanophore } \\
\text { pattern }\end{array}$ & No pigment & No pigment \\
\hline $\begin{array}{c}\text { On top of brain } \\
M_{\mathrm{H}}\end{array}$ & $\begin{array}{l}\text { Distinct merging } \\
\text { into a solid cap }\end{array}$ & All separate & No pigment & No pigment \\
\hline
\end{tabular}

\section{Statistical Analyses}

Mean values of $L_{\mathrm{S}}$ and mass did not show any significant difference between the females from which pre-extruded larvae were extracted and selected (both $P>0,5$ ); for this reason, the maternal influences [age, size and condition of females on egg and larval quality (Sogard et al., 2008)] were not considered in this study.

The means of each variable between species were compared by $t$-test. This study used a $t$-Test for unequal variances (the homogeneity assumption could have been violated, indicated by the Levene test), because the results between equal variances and unequal variances were practically indistinguishable (Zar, 1999).

Discriminant analysis (Bookstein, 1991) was used to identify characters with the best potential for future classification of planktonic larvae (classification power of each morphological character, using stepwise insertion of variables). Stepwise insertions of variables were used to minimize the sum of unexplained variance for all groups and to eliminate redundant variables. Three different discriminant functions were determined: (1) only morphometric variables were used, (2) only meristic and pigmentation patterns were used and (3) all variables and measurements were combined. Although discriminant analysis assumes that the discriminating variables have normal distributions, in practice, strict adherence to the technique is not required (Mardia et al., 1992). Statistical analyses were carried out using IBM SPSS Statistics 19 for Windows (www01.ibm.com/software/analytics/spss/products/statistics). 


\section{RESULTS}

Larvae collected from adult $S$. mentella were larger than those from $S$. norvegicus; mean $L_{\mathrm{S}}$ was significantly different (Table II). Similarly, body and head depth, eye diameter and pre-anal length were larger in $S$. mentella. Therefore, larvae of $S$. mentella appeared deeper bodied than those of $S$. norvegicus (Fig. 2). The ventral and dorsal rows of postanal melanophores, however, were longer in S. norvegicus (Table III).

Meristic and pigmentation variables were found to have significantly different means, except for the postanal myomere on which the posteriormost melanophore on the dorsum ends ( $M_{\mathrm{D}-\mathrm{E}}$; Table III). Larvae of $S$. norvegicus tended to have more total body myomeres as well as more postanal and preanal myomeres than $S$. mentella [Fig. 3(a)]. The caudal (posterior) ends of the pigment pattern on the dorsum $\left(M_{\mathrm{D}-\mathrm{E}}\right)$ and ventrum $\left(M_{\mathrm{V}-\mathrm{E}}\right)$ were similar for most larvae of both species [Fig. 3(b), (c)].

Table II. Morphometric measurements of pre-extrusion larvae of Sebastes mentella and Sebastes norvegicus.

\begin{tabular}{cccccc}
\hline & $\begin{array}{c}\text { Mean } \pm \text { S.E. } \\
L_{\mathrm{S}}(\mathrm{mm})\end{array}$ & $\begin{array}{c}\text { Mean } \pm \mathrm{S} . \mathrm{E} \\
B_{\mathrm{D}}(\mathrm{mm})\end{array}$ & $\begin{array}{c}\text { Mean } \pm \mathrm{S} . \mathrm{E} \\
L_{\mathrm{PRA}}(\%)\end{array}$ & $\begin{array}{c}\text { Mean } \pm \mathrm{S} . \mathrm{E} \\
H_{\mathrm{D}}(\mathrm{mm})\end{array}$ & $\begin{array}{c}\text { Mean } \pm \mathrm{S} . \mathrm{E} \\
D_{\mathrm{E}}(\mathrm{mm})\end{array}$ \\
\hline S. mentella & $7.43 \pm 0.04$ & $1.33 \pm 0.01$ & 34 & $1.44 \pm 0.01$ & $0.64 \pm 0.007$ \\
S. norvegicus & $6.18 \pm 0.03$ & $1.08 \pm 0.01$ & 33 & $1.20 \pm 0.01$ & $0.55 \pm 0.005$ \\
$t$-Test & 23.24 & 11.43 & 18.13 & 15.48 & 10.76 \\
$P$ & $<0.05$ & $<0.05$ & $<0.05$ & $<0.05$ & $<0.05$ \\
\hline
\end{tabular}

$L_{\mathrm{S}}$, standard length; $B_{\mathrm{D}}$, body depth; $L_{\mathrm{PRA}}$, pre-anal length; $H_{\mathrm{D}}$, head depth; $D_{\mathrm{E}}$, eye diameter.

Table III. Comparison of means of all meristic and pigmentation variables for Sebastes mentella and Sebastes norvegicus.

\begin{tabular}{|c|c|c|c|c|c|c|c|c|c|c|c|c|c|}
\hline & $M_{\mathrm{PRA}}$ & $M_{\mathrm{POA}}$ & $M$ & $\boldsymbol{P}_{\mathrm{D}-\mathrm{B}}$ & $P_{\mathrm{D}-\mathrm{E}}$ & $\boldsymbol{P}_{\mathrm{V}-\mathrm{B}}$ & $\boldsymbol{P}_{\mathrm{V}-\mathrm{E}}$ & $\boldsymbol{P}_{\mathrm{D}-\mathrm{T}}$ & $P_{\mathrm{V}-\mathrm{T}}$ & $\boldsymbol{P}_{\mathrm{V}}$ & $\boldsymbol{P}_{\mathrm{N}}$ & $\boldsymbol{P}_{\mathrm{D}}$ & $\boldsymbol{P}_{\mathrm{H}}$ \\
\hline S. mentella & 7.11 & 23.20 & 30.31 & 14.43 & 21.67 & 7.74 & 21.89 & 8.26 & 15.22 & 3.24 & 1.83 & 1.09 & 1.5 \\
\hline S. norvegicus & 7.68 & 23.96 & 31.64 & 9.89 & 21.45 & 4.79 & 22.23 & 12.57 & 18.43 & 2.00 & 3.00 & 1.00 & 2.00 \\
\hline t-test & -7.30 & -7.03 & -11.75 & 18.42 & 1.34 & 13.65 & -2.10 & -15.85 & -12.71 & 21.13 & -8.70 & 2.33 & -7.28 \\
\hline $\mathrm{P}$ & $<0.05$ & $<0.05$ & $<0.05$ & $<0.05$ & $>0.05$ & $<0.05$ & $<0.05$ & $<0.05$ & $<0.05$ & $<0.05$ & $<0.05$ & $<0.05$ & $<0.05$ \\
\hline
\end{tabular}

$M$, total body myomeres; $M_{\mathrm{PRA}}$, number of pre-anal myomeres; $M_{\mathrm{POA}}$, number of postanal myomeres; $P_{\mathrm{D}-\mathrm{B}}$, postanal myomere on which the anteriormost melanophore on the dorsum begins; $P_{\mathrm{D}-\mathrm{E}}$, postanal myomere on which the anteriormost melanophore on the dorsum ends; $P_{\mathrm{V}-\mathrm{B}}$, postanal myomere on which the anteriormost melanophore on the ventrum begins; $P_{\mathrm{V}-\mathrm{E}}$, postanal myomere on which the anteriormost melanophore on the ventrum ends; $P_{\mathrm{D}-\mathrm{T}}$, total length, in myomeres, of the dorsal body melanophore line; $P_{\mathrm{V}-\mathrm{T}}$, total length, in myomeres, of the ventral body melanophore line; $P_{\mathrm{V}}$, melanophore pattern located on the ventrum; $P_{\mathrm{N}}$, melanophore pattern located at the nape; $P_{\mathrm{D}}$, melanophore pattern located on the dorsum; $P_{\mathrm{H}}$, melanophore pattern located on top of the brain.

Pigmentation patterns differed between species. The most noticeable difference was the line of melanophores on the ventrum; in $S$. norvegicus these were closely spaced dots (expanded, not separate). Also, in $S$. norvegicus the start of the pigment pattern on the dorsum $\left[P_{\mathrm{D}-\mathrm{B}} ;\right.$ Fig. $\left.3(\mathrm{~b})\right]$ and ventrum $\left[P_{\mathrm{V}-\mathrm{B}}\right.$; Fig. $\left.3(\mathrm{c})\right]$ tended to be more anterior than in $S$. mentella. The lengths of the dorsal and ventral melanophore patterns $\left(P_{\mathrm{D}-\mathrm{T}}\right.$ and $\left.P_{\mathrm{V}-\mathrm{T}}\right)$ for $S$. mentella were shorter, when measured in 
myomere units, than the corresponding patterns in S. norvegicus [Fig. 3(b), (c)]. Neither species had subcaudal melanophores.

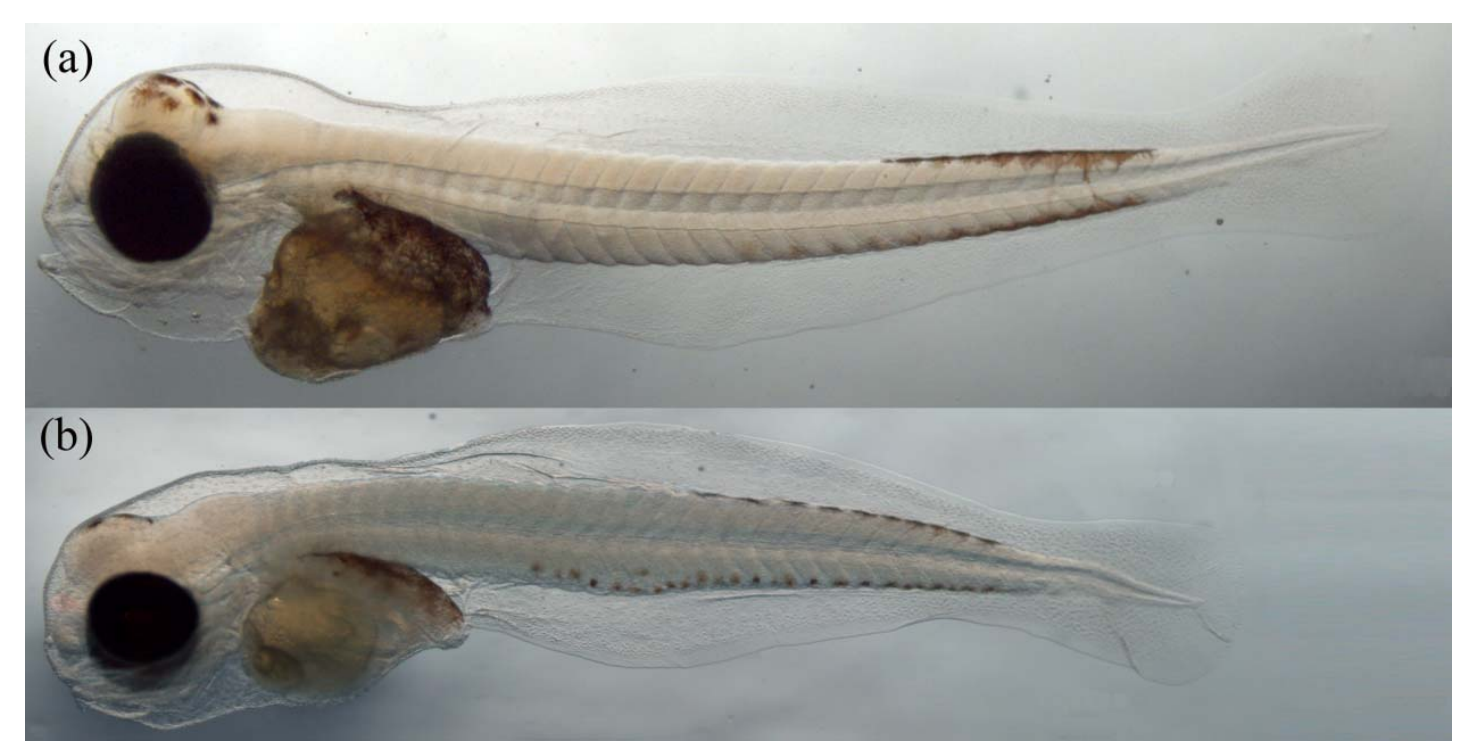

Fig. 2. Pre-extruded larvae: (a) Sebastes mentella (7,6mm standard length, $\left.L_{\mathrm{S}}\right)$ and (b) Sebastes norvegicus $\left(6,3 \mathrm{~mm} L_{\mathrm{S}}\right)$.

A discriminant analysis performed on the morphometric, meristic and pigmentation variables of pre-extrusion larvae of $S$. mentella and $S$. norvegicus showed that it is possible to separate the two species. The discriminant analysis explained $100 \%$ of the variance and discriminates between the species: $97,8 \%$ of pre-extrusion larvae were correctly classified according to their morphometric variables, $100 \%$ of preextrusion larvae were correctly classified according to their meristic and pigmentation traits and all variables combined. The difference in the centroids of morphological, meristic and pigmentation traits was significant (see Wilk's $\lambda$ and $\chi^{2}$ in Table IV).

Nevertheless, none of the characters would, individually, allow a positive identification at the species level. Pooling characters into discriminant functions improved the usefulness of the individual characters. When only morphometric variables were used, pre-extrusion larvae mainly differed between species in $L_{\mathrm{S}}$, eye diameter and head depth (Table IV); most of the classification power of this function relied on these three variables. None of the other morphometric traits increased the number of cases correctly classified. When only meristic and pigmentation variables were used, the resultant discriminant function included six useful variables (Table IV). The variables included characteristics of pigmentation patterns on the ventrum, dorsum and head; in $S$. norvegicus the ventral pigmentation was mainly represented by small expanded melanophores, whereas $S$. mentella had larger expanded and contracted melanophores on the ventrum (Table III). The third discriminant function, based on all variables combined, identified five useful variables (Table IV). Therefore, discriminant analysis described differences in morphological, meristic and pigmentation traits.

\section{DISCUSSION}

The results of this study are compatible with those of Magnússon (1981), who reported a definite size difference between larvae of $S$. norvegicus and $S$. mentella at the time of extrusion. 
Additionally, this study reveals significant morphometric, meristic and pigmentation differences between pre-extrusion larvae of $S$. mentella and $S$. norvegicus in Icelandic waters (Table III). Morphologically, pre-extrusion larvae of $S$. mentella can be characterized as deeper bodied than those of $S$. norvegicus, as evidenced by their relatively greater $L_{S}$, body depth and head depth (Table II). The larvae of Sebastes mentella have larger eye diameters and greater pre-anal lengths than those of $S$. norvegicus. This observation, together with the findings of Magnússon \& Magnússon (1977), suggests that larvae of $S$. mentella are larger at extrusion than those of $S$. norvegicus.

Table IV. Canonical discriminant functions, eigenvalues, \% of variance, canonical correlation, Wilk's $\lambda$ and $\chi^{2}$ for the discriminant analysis of characteristics of pre-extruded larvae of Sebastes mentella and Sebastes norvegicus. Only largest coefficients for each function are shown.

\begin{tabular}{lccc}
\hline & \multicolumn{3}{c}{ Discriminant function } \\
\cline { 2 - 4 } & Morphometrics & Meristic and pigmentation & All variables \\
\hline$L_{\mathrm{S}}$ & 0.781 & & 0.585 \\
$H_{\mathrm{D}}$ & 0.366 & & 0.372 \\
$D_{\mathrm{E}}$ & 0.348 & 0.305 & \\
$P_{\mathrm{D}}$ & & -0.883 & \\
$P_{\mathrm{V}}$ & & 0.578 & 0.765 \\
$P_{\mathrm{H}}$ & & -0.547 & -0.367 \\
$P_{\mathrm{D}-\mathrm{B}}$ & & 0.413 & \\
$P_{\mathrm{V}-\mathrm{T}}$ & & 0.398 & -0.636 \\
$M_{\mathrm{POA}}$ & & 15.271 & \\
Eigenvalue & & 100 & 19.455 \\
$\%$ of variance & 1.093 & 0.969 & 100 \\
Cannonical correlation & 0.936 & 0.061 & 0.975 \\
Wilk`s lambda & 0.124 & 284.52 & 0.049 \\
$\chi^{2 *}$ & 201.78 & 288.24 \\
\hline
\end{tabular}

$L_{\mathrm{S}}$, standard length; $H_{\mathrm{D}}$, head depth; $D_{\mathrm{E}}$, eye diameter; $P_{\mathrm{V}}$, melanophore pattern located on the ventrum; $P_{\mathrm{D}}$, melanophore pattern located on the dorsum; $P_{\mathrm{H}}$, melanophore pattern located on top of the brain; $P_{\mathrm{D}-\mathrm{B}}$, postanal myomere on which the anteriormost melanophore on the dorsum begins; $P_{\mathrm{V}-\mathrm{T}}$, the ventral body melanophore line; $M_{\mathrm{POA}}$, number of postanal myomeres. $* P<0,05$

In terms of meristics, Icelandic populations of $S$. mentella larvae have 29-32 total body myomeres, whereas $S$. norvegicus have 30-33. Despite overlap, the range of total myomeres found in this work for $S$. mentella and $S$. norvegicus is greater than the range reported by other authors (Table V). Evidently, there is geographic variation in these meristics, but this might also be compounded by differing methods of identification (Penney, 1985). On the other hand, the results of this study of frequency distribution of body myomeres of melanophore patterns on the dorsum and on the ventrum for $S$. mentella are compatible with those of Penney (1985) (see Fig. 3).

Pigmentation of $S$. mentella differs from that of $S$. norvegicus in several aspects. The dorsal and ventral body pigmentation tends to begin more posteriorly in S. mentella than in S. norvegicus; therefore, these pigmented areas tend to be longer overall in S. norvegicus. Moser et al. (1977) and Fahay (1983) reported for $S$. norvegicus the total number of melanophores in the dorsal and ventral row from 8 to 21 and 11 to 24 , respectively; in samples of pre-extrusion larvae of $S$. norvegicus 
from Icelandic waters, the frequency distributions of these characters have a shorter range (one melanophore per one myomere, Fig. 3).
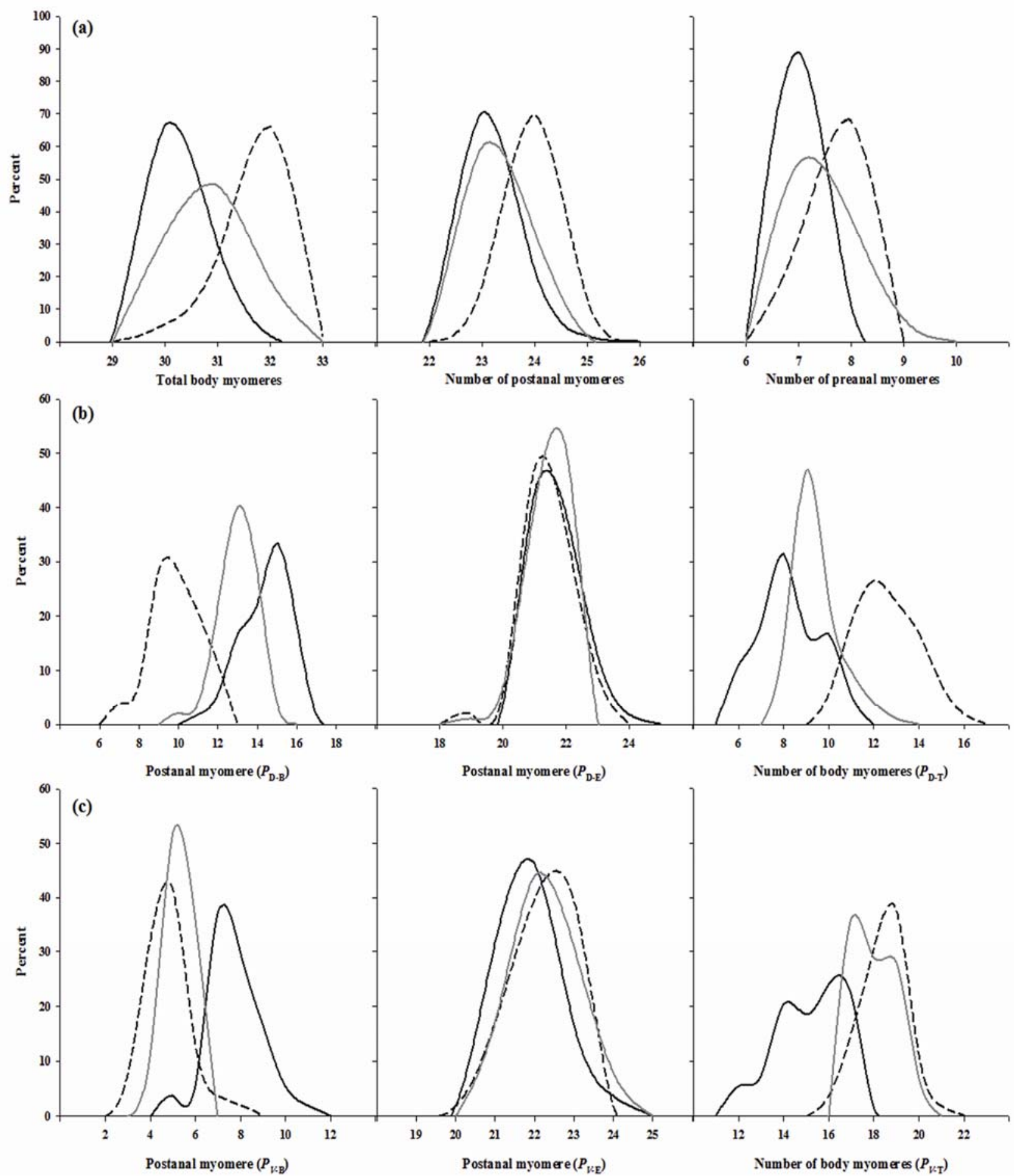

Fig. 3. Pre-extruded larvae of Sebastes mentella and Sebastes norvegicus. Frequency distributions of (a) body myomeres, (b) melanophore patterns on the dorsum and (c) melanophore patterns on the ventrum [---, S. norvegicus; S. mentella; , S. mentella (Penney, 1985)].

The presence of one or more subcaudal melanophores in some of the larvae of $S$. mentella from the Labrador and Newfoundland areas distinguishes them in this respect from the basic S. mentella stocks off the region extending from south-west Iceland and south of Greenland to north of Flemish 
Cap, whose larvae were reported to have no subcaudal melanophores (Kotthaus, 1961; Henderson, 1965; Bainbridge \& Cooper, 1971; Templeman, 1980; Serebryakov, 1982). In this study, preextrusion larvae of both $S$. mentella and $S$. norvegicus lack subcaudal melanophores. It is possible that the presence of melanophores in some of the larvae of $S$. mentella from the North American shelf and slope areas indicates interbreeding, presumably with Sebastes fasciatus Storer 1854 (Templeman, 1980). The larvae of $S$. norvegicus in some samples from the North American shelf areas possess more subcaudal melanophores than those from other North Atlantic Ocean regions (Templeman, 1980).

Table V. Standard length $\left(L_{\mathrm{S}}\right)$ and number of body myomeres found in pre-extrusion larvae of Sebastes mentella and Sebastes norvegicus.

\begin{tabular}{|c|c|c|c|c|}
\hline & $\begin{array}{l}\text { Hatching } \\
\left(L_{S} \mathrm{~mm}\right)\end{array}$ & $\begin{array}{c}\text { Number of body } \\
\text { myomeres }\end{array}$ & Locality & Reference \\
\hline \multirow[t]{5}{*}{ S. mentella } & $7-9$ & & & Barsukov et al. (1985) \\
\hline & $7.0-11$ & $28-31$ & $\begin{array}{l}\text { Northern part of the } \\
\text { north-west Atlantic } \\
\text { Ocean }\end{array}$ & Serebryakov (1982) \\
\hline & & $30-32$ & $\begin{array}{l}\text { Western North Atlantic } \\
\text { Ocean }\end{array}$ & Fahay (1983) \\
\hline & & $30-32$ & $\begin{array}{l}\text { South coast of } \\
\text { Newfoundland }\end{array}$ & Penney (1985) \\
\hline & $6.8-8.1$ & $29-32$ & Iceland & This work \\
\hline \multirow[t]{6}{*}{ S. norvegicus } & $6-8$ & & & Barsukov et al. (1985) \\
\hline & $6.5-7.3$ & & & Colton \& Marak (1969) \\
\hline & $6.7-7.2$ & & & Moser et al. (1977) \\
\hline & & $28-30$ & $\begin{array}{l}\text { Northern part of the } \\
\text { north-west Atlantic } \\
\text { Ocean }\end{array}$ & Serebryakov (1982) \\
\hline & & $30-32$ & $\begin{array}{l}\text { Western North Atlantic } \\
\text { Ocean }\end{array}$ & Fahay (1983) \\
\hline & $5.8-6.6$ & $30-33$ & Iceland & This work \\
\hline
\end{tabular}

The presence, in Icelandic waters and other parts of the North Atlantic Ocean, of three species of Sebastes (S. mentella, S. norvegicus and S. fasciatus), of which the two sharp-beaked mentella-type species ( $S$. mentella and $S$. norvegicus) are similar in appearance and usually more numerous, offers obvious challenges for management, as these species are now treated as a single group for management purposes. Consequently, the diagnosis of the species is still very difficult (Barsukov et al., 1985; Sévigny et al., 2000). Nevertheless, identifications of any specimens may be possible with genetic methods (e.g. DNA sequence data; Rocha-Olivares, 1998; Sakuma et al., 2005). Sebastes mentella and S. norvegicus tend to live at different depths, release larvae at different times, differ in size at first reproduction and presumably differ in growth rates, with potential differences in the nursery areas inhabited by the juveniles. The larvae are affected differently by currents, temperature conditions and plankton blooms, with consequent effects on larval growth and mortality (Templeman, 1980). The differences observed in this study, between pre-extruded larvae of $S$. mentella and $S$. norvegicus, could be owing to spatial population differences in pigment expression at the genetic level, or spatial differences in environmental factors, such as temperature, affecting larval development. Such variability in environmental conditions could also possibly affect larval fish development, which might be expressed in pigment variability (Sakuma et al., 2005). 
The resultant 98,9-100\% correct classification according to morphometric, meristic and pigmentation variables reported in this study, of pre-extruded larvae, is encouraging, particularly in its potential applicability to new research on early life history of these species. Development of discriminant functions based on characteristics of pre-extrusion larvae of known species, and subsequent extrapolation to young planktonic larvae may finally prove to be an effective identification tool for larval Sebastes in the North Atlantic Ocean.

Accurate identification of larval and pelagic juvenile Sebastes is important for their use in biomass estimates and recruitment studies. Very few Sebastes species, however, can be accurately identified throughout their entire early life history based on morphological, meristic and pigment characters alone. Spatial variability in pigment patterns is difficult to account for because of the lack of complete descriptions of early life history for many species of Sebastes (Kendall, 1991; Moser, 1996), and should be taken into consideration when examining larvae from different geographic locations. The results presented in this article are a first step to demonstrate a new approach to determining the differences between pre-extruded larvae of $S$. norvegicus and $S$. mentella in Icelandic waters and help to complete the descriptions of their early life history. Despite the potential constraints noted above, the type of analysis presented here seems promising.

The author is grateful to F. Saborido-Rey for providing gonads with pre-extrusion larvae from the Redfish project and for the privilege of using previously collected data. Also, the authors wish to thank E. Heseltine and an anonymous reviewer for useful comments on the manuscript. Funding for A.R.V. was provided by the Xunta de Galicia (Programa Isidro Parga Pondal).

\section{References}

Bainbridge, V. \& Cooper, G. A. (1971). Populations of Sebastes larvae in the North Atlantic. International Commission for the Northwest Atlantic Fisheries Research Bulletin 8, 27-35.

Barsukov, V. V., Litvinenko, N. I. \& Serebryakov, V. P. (1985). Manual for the identification of redfish species of the north Atlantic and adjacent areas. Canadian Translation of Fisheries and Aquatic Sciences 5168, 3-28 (original in Russian. Kalingrad. Ministry of Fisheries of the U.S.S.R, 1984).

Bookstein, F. (1991). Morphometric Tools for Landmark Data: Geometry and Biology. Cambridge: Cambridge University Press.

Colton, J. B. Jr. \& Marak, R. R. (1969). Guide for identifying the common planktonic fish eggs and larvae of continental shelf waters, Cape Sable to Block Island. Reference Document No. 69-9. Woods Hole, MA: U.S. National Marine Fisheries Service, Northeast Fisheries Center.

Fahay, M. P. (1983). Guide to the early stages of marine fishes occurring in the Western North Atlantic Ocean, Cape Hatteras to the Southern Scotian Shelf. Journal of Northwest Atlantic Fishery Science 4, 3-423.

Gray, A. K., Kendall, A. W. Jr., Wing, B. L., Carls, M. G., Heifet, J., Li, Z. \& Gharrett, A. J. (2006). Identification and first documentation of larval rockfishes in southeast Alaskan waters was possible using mitochondrial markers but not pigmentation patterns. Transactions of the American Fisheries Society 135, 1-11.

Henderson, G. T. D. (1965). Redfish larvae in the North Atlantic. International Commission for the Journal of Northwest Atlantic Fishery Science Special Publication 6, 309-315. 
Kendall, A. W. Jr. (1991). Systematics and identification of larvae and juveniles of the genus Sebastes. Environmental Biology of Fishes 30, 173-190.

Kotthaus, A. (1961). Contributions to the race problem in redfish. Journal du Conseil permanent international pour l'Exploration de la Mer 150, 42-44.

Magnússon, J. V. (1981). Identification of Sebastes marinus, S. mentella, and S. viviparus in 0group redfish. Journal du Conseil permanent international pour l'Exploration de la Mer 178, 571-574.

Magnússon, J. \& Magnússon, J. V. (1995). Oceanic redfish (Sebastes mentella) in the Irminger Sea and adjacent waters. Scientia Marina 59, 241-254.

Mardia, D. S., Kent, J. T. \& Bibby, J. M. (1992). Multivariate Analysis, 10th edn. New York, NY: Academic Press.

Matarese, A. C., Kendall, A. W. Jr., Blood, D. M. \& Vinter, B. M. (1989). Laboratory guide to the early life history stages of Northeast Pacific fishes. NOAA Technical Report NMFS $\mathbf{8 0 .}$

Moser, H. G. (1996). Scorpaenidae: scorpionfishes and rockfishes. In The Early Stages of Fishes in the California Current Region, California Cooperative Oceanic Fisheries Investigation, Atlas 33 (Moser, H. G., ed), pp. 733-795. Lawrence, KS: Allen Press.

Moser, H. G. \& Boehlert, G. W. (1991). Ecology of pelagic larvae and juveniles of the genus Sebastes. Environmental Biology of Fishes 30, 203-224.

Moser, H. G., Ahlstrom, E. H. \& Sandknop, E. M. (1977). Guide to the identification of scorpionfish larvae (family Scorpaenidae) in the eastern Pacific with comparative notes on species of Sebastes and Helicolenus from other oceans. NOAA Technical Repor NMFS Circular 402, 1-71.

Ni, I. H. (1982). Meristic variation in beaked redfishes, Sebastes mentella and S. fasciatus, in the Northwest Atlantic. Canadian Journal of Fisheries and Aquatic Sciences 39, 1664-1685.

Pampoulie, C. \& Daníelsdóttir, A. K. (2008). Resolving species identification problems in the genus Sebastes using nuclear genetic markers. Fisheries Research 93, 54-63.

Penney, R. W. (1985). Comparative morphology of pre-extrusion larvae of North American sharpbeaked redfishes Sebastes mentella and Sebastes fasciatus (Pisces: Scorpaenidae). Canadian Journal of Zoology 63, 1181-1188.

Penney, R. W. (1987). Development of deep-water redfish (Sebastes mentella) larvae with comparative notes on newly extruded Acadian redfish (Sebastes fasciatus) from the Flemish Cap. Canadian Journal of Zoology 65, 1167-1180.

Power, D. J. \& Ni, I. H. (1985). Morphometric differences between golden redfish Sebastes marinus) and beaked redfish (S. mentella and S. fasciatus). Journal of Northwest Atlantic Fishery Science 6, 1-7.

Rocha-Olivares, A. (1998). Multiplex haplotype-specific PCR: a new approach for species identification of the early life stages of rockfishes of the species-rich genus Sebastes Cuvier. Journal of Experimental Marine Biology and Ecology 231, 279-290.

Rubec, P. J., McGlade, J. M., Trottier, B. L. \& Ferron, A. (1991). Evaluation for methods for separation of Gulf of Saint-Lawrence beaked redfishes, Sebastes fasciatus and S. mentella: malate dehydrogenase mobility patterns compared with extrinsic gasbladder muscle passages and anal fin ray counts. Canadian Journal of Fisheries and Aquatic Sciences 48, 640-660.

Saborido-Rey, F. (1994). The genus Sebastes Cuvier, 1829 (Pisces, Scorpaenidae) in the North Atlantic: species and population identification using morphometric techniques; growth and reproduction of the Flemish Cap populations. PhD Thesis, University Autónoma Madrid, Madrid, Spain (in Spanish). 
Saborido-Rey, F., Garabana, D. \& Cerviño, S. (2004). Age and growth of redfish (Sebastes marinus, S. mentella, and S. fasciatus) on the Flemish Cap (Northwest Atlantic). ICES Journal of Marine Science 61, 231-242.

Sakuma, K. M., Taylor, C. A. \& Watson, W. (2005). Pigment variability in larval Sebastes jordani off central California. Journal of Fish Biology 67, 510-520.

Serebryakov, V. P. (1982). A key for identification of ichthyoplankton from the Northwest Atlantic (Shelf waters north of the Cabot Strait). NAFO SCR Document 82/VI/31 Serial N519.

Serebryakov, V. P., Astafjeva, A. V., Aldonov, V. K. \& Chumakov, A. K. (1984). USSR ichthyoplankton investigations within the framework to the Flemish Cap project in 19781983. USSR NAFO SCR Document 84/IX/95 Serial N890.

Sévigny, J. M., De Gagné, P., Lafontaine, Y. \& Dodson, J. (2000). Identification and distribution of the larvae of redfish species (Sebastes fasciatus and S. mentella: Scorpaenidae) in the Gulf of St. Lawrence. Fisheries Bulletin 98, 375-388.

Sogard, S. M., Berkeley, S. A. \& Fisher, R. (2008). Maternal effects in rockfishes Sebastes spp.: a comparison among species. Marine Ecology Progress Series 360, 227-236.

Templeman, W. (1980). Incidence of subcaudal melanophores in pre-extrusion larvae of redfish species in the Newfoundland-Labrador area. Journal of Northwest Atlantic Fishery Science 1, 7-19.

Zar, J. H. (1999). Biostatistical Analysis, 4th edn. Upper Saddle River, NJ: Prentice Hall.

\section{Electronic References}

Eschmeyer, W. N. (2012). Catalog of Fishes. California Academy of Sciences. Available at http://research.calacademy.org/research/ichthyology/catalog/fishcatmain.asp/ (accessed 8 August 2012).

Magnússon, J. V. \& Magnússon, J. (1977). On the distinction between larvae of $S$. marinus and $S$. mentella, preliminary report. ICES CM $1977 \quad / F: 48$. Available at http://www.hafro.is/Bokasafn/Greinar/ices_1977_F48.pdf/ (accessed 19 March 2013). 